\title{
Study of the More Suitable Drugs and Dosage Forms for Administration to Newborn Infants via Feeding Tube Using the Collection Rate as an Indicator
}

\author{
Yoshihito Shimizu,* Masatoshi Taga, Yoshimitsu Takahashi, Iku Tada, Fumiyuki Takase, \\ Osamu Niwa, and Togen Masauji \\ Department of Pharmacy, Kanazawa Medical University Hospital; 1-1 Daigaku. Uchinada, Kahoku, \\ Ishikawa 920-0293, Japan. \\ Received February 20, 2020; accepted May 7, 2020
}

The dosages of drugs in newborn infants are small. Small dose necessitate consideration of the loss of drug when administered via feeding tube. In this study, we conducted a tube administration test for seven kinds of antiepileptic drugs and two kinds of potassium supplements using a neonatal feeding tube and investigated the drug loss using the collection rate. We also studied the differences in collection rates among different dosage forms and drugs to determine the more suitable dosage forms and drugs. We investigated three dosage forms: powder, fine granules or dry syrup (powdery form) drugs, powdery form drugs that have been pulverized (pulverized powdery forms), and pulverized tablets. Additionally, we investigated two potassium supplements to determine which was more suitable: potassium L-aspartate and potassium gluconate. For topiramate, only the powdery form caused tube obstructions; the collection rates of the pulverized powdery form and pulverized tablets were $>\mathbf{9 0 \%}$. All antiepileptic drugs other than topiramate that were tested had collection rates of about $>\mathbf{9 0} \%$. Considering stability and pharmacokinetics, the more suitable dosage form for topiramate is pulverized tablets, whereas the more suitable dosage form for other antiepileptic drugs is powdery form. Collection rate of potassium gluconate was higher than that of potassium L-aspartate. The current study, which indicates that potassium gluconate powdery form is the more suitable drug, presents the more suitable dosage form and drug for administration via feeding tube to newborn infants. These results show that it is essential to evaluate passage through the tube using the collection rate.

Key words collection rate; tube passage; neonate; feeding tube administration

\section{Introduction}

In cases where newborn infants are unable to swallow owing to prematurity, neuromuscular disease, or developmental delays, drugs are administered via feeding tube. ${ }^{1,2)}$ An issue with administration via feeding tube is that drugs can get deposited on the inside of the tube or entirely obstruct the tube, leading to the loss of some amount of drug. ${ }^{3,4)}$ Particularly, tubes with small diameters designed for pediatric feeding are susceptible to obstructions. ${ }^{4)}$ Powder, fine granules or dry syrup (powdery form) drugs are often selected as the dosage form for pharmacotherapy in newborn infants; however, it has been shown that switching from pulverized powdery forms or powdery forms to pulverized tablets increases passage of drugs through the tubes. ${ }^{5)}$ Additionally, drugs that easily cause obstructions are avoided to prevent tube obstructions; it is important to select a drug with a similar efficacy that will not cause an obstruction in the tube. ${ }^{3)}$

The dosage of drugs for newborn infants is precisely determined based on the infant's body weight. ${ }^{6}$ Because the dosage is much lower in infants than that in adults, the loss of drug during feeding tube must be carefully considered. However, most information on the passage of drugs through feeding tubes applies to adults, ${ }^{3,7)}$ and information on administration via feeding tube in newborn infants is lacking. Thus, we conducted tests on the passage of drugs through feeding tubes using different dosage forms and drugs by comparing the collection rates of solutions passed through feeding tubes to investigate more appropriate dosage forms and drugs for tube administration to newborns.

\section{Experimental}

Drugs Used in This Study Our hospital uses both powdery forms and tablets for antiepileptic drugs and potassium supplements, drugs for which loss owing to feeding tube is particularly important. This study was conducted on of potassium L-aspartate and potassium gluconate, an alternative to potassium L-aspartate, because potassium L-aspartate is reported to be liable to cause obstructions in tubes in our hospital.

Dosage Forms Studied For antiepileptic drugs, three dosage forms were studied: powdery form, pulverized powdery form, and pulverized tablets. Because potassium supplement tablets are highly hygroscopic, they cannot be pulverized ${ }^{8}$; therefore, only powdery form and pulverized powdery form were studied. Powdery forms were pulverized for $1 \mathrm{~min}$ in a KC-HUK tablet grinder (Konishi-Seisakusho Co., Ltd., Osaka, Japan). Tablets were pulverized using a mortar and pestle followed by sieving.

Setting Drug Dosages Using Passage Experiments The set value for antiepileptic drugs assumes a standard body weight of $3 \mathrm{~kg}$ for newborn infant patients. The ingredient amounts were set as per the package insert and literature. ${ }^{6,9)}$ At our hospital, drug dosages of $<0.200 \mathrm{~g}$ are supplemented with lactose to make up the weight up to $0.200 \mathrm{~g}$ as per pharmacy bylaws. The potassium dosage was set in accordance with the serum potassium levels of individual patient; hence, 
Table 1. Target Drug and Set Amount

\begin{tabular}{|c|c|c|c|}
\hline Active ingredient & Brand Name & Company (Location) & Set Amount ${ }^{a)}$ \\
\hline Carbamazepin & $\begin{array}{l}\text { Tegretol }^{\circledR} \text { Fine Granules } 50 \% \\
\text { Tegretol }^{\circledR} \text { Tablets } 100 \mathrm{mg}\end{array}$ & Mitsubishi Tanabe Pharma Corp. (Osaka) & $30 \mathrm{mg}$ \\
\hline Clonazepam & $\begin{array}{l}\text { Rivotril }^{\circledR} \text { Fine Granule } 0.1 \% \\
\text { Rivotril }^{\mathbb{B}} \text { Tablets } 1 \mathrm{mg}\end{array}$ & Taiyo Pharma Co., Ltd. (Tokyo) & $0.3 \mathrm{mg}$ \\
\hline Zonisamide & $\begin{array}{l}\text { Excegran }^{\circledR} \text { Powder } 20 \% \\
\text { Excegran }^{\circledR} \text { Tablet } 100 \mathrm{mg}\end{array}$ & Sumitomo Dainippon Pharma Co., Ltd. (Osaka) & $24 \mathrm{mg}$ \\
\hline Topiramate & $\begin{array}{l}\text { Topina }{ }^{\circledR} \text { Fine Granules } 10 \% \\
\text { Topina }{ }^{\circledR} \text { Tablets } 50 \mathrm{mg}\end{array}$ & Kyowa Kirin Co., Ltd. (Tokyo) & $9 \mathrm{mg}$ \\
\hline Phenytoin & $\begin{array}{l}\text { Aleviatin }{ }^{\circledR} \text { Powder } 10 \% \\
\text { Hydantol }^{\circledR} \text { Tablets } 25 \mathrm{mg}\end{array}$ & $\begin{array}{l}\text { Sumitomo Dainippon Pharma Co., Ltd. (Osaka) } \\
\text { Daiichi Sankyo Company, Limited (Tokyo) }\end{array}$ & $12 \mathrm{mg}$ \\
\hline Primidone & $\begin{array}{l}\text { Primidone Fine Granules } 99.5 \% \text { "Nichiiko" } \\
\text { Primidone Tablets } 250 \mathrm{mg} \text { "Nichiiko" }\end{array}$ & Nichi-Iko Pharmaceutical Co., Ltd. (Toyama) & $45 \mathrm{mg}$ \\
\hline Levetiracetam & $\begin{array}{l}\text { E Keppra }{ }^{\circledR} \text { Dry syrup } 50 \% \\
\text { E Keppra }^{\circledR} \text { Tablets } 500 \mathrm{mg}\end{array}$ & Otsuka Pharmaceutical Co., Ltd. (Tokyo) & $30 \mathrm{mg}$ \\
\hline Potassium L-aspartate & Aspara ${ }^{\circledR}$ Potassium Powder $50 \%$ & Nipro ES Pharma Co., Ltd. (Osaka) & $0.2 \mathrm{~g}$ \\
\hline Potassium gluconate & Gluconsan K Fine Granules $4 \mathrm{mEq} / \mathrm{g}$ & Pola Pharma Inc. (Tokyo) & $0.8 \mathrm{~g}$ \\
\hline
\end{tabular}

a) Antiepileptic drugs are indicated by component amounts, and potassium supplement are indicated by formulation amount.

the dose of potassium L-aspartate was set at $0.200 \mathrm{~g}$. The set dosage for potassium gluconate was $0.800 \mathrm{~g}$, with reference to the single administration dose ratio with potassium L-aspartate $(0.6: 2.5 \mathrm{~g})$ listed on the package insert. The ingredient names, product names, and set doses are summarized in Table 1.

Measurement of Powder Temperature before and after Using the Tablet Grinder In order to investigate the effect of heat generated during use of the grinder on the tablet, the temperature of the powder before and after the pulverization was measured with a probe thermometer (Inkbird Tech. Co., Ltd., China) for three times. After the temperature was measured, the mixture was pulverized for 1 min using a grinder, and the temperature immediately after pulverization was measured.

Equipment Used for Passage Tests The 5-mL syringes for Nipro catheters used at our hospital (NIPRO Medical Corporation, Osaka, Japan) were used as injectors. The feeding tubes used were J-feed feeding catheters with imaging lines (5 FR/40 cm; JMS Co., Ltd., Hiroshima, Japan), which are the most frequently used tubes in the NICU at our hospital. Mini clear cups (Yuei Co., Ltd., Osaka, Japan) were used as suspension cups.

Passage Tests Passage tests and collection rate calculations were performed using simple suspension methods described by Niimura et al. ${ }^{10)}$ and Ruzsíková et al. ${ }^{11)}$ The set dose of each drug was accurately weighed in a suspension cup, and then $5.0 \mathrm{~mL}$ of $55^{\circ} \mathrm{C}$ tap water was added to make a solution. After letting it rest for $10 \mathrm{~min}$, the suspended solution for administration via feeding tube was drawn up and down 15 times using an injector, then drawn up and connected to a feeding tube, two-third (from the end that is inserted into the body) of which was lying horizontally to simulate an infant patient lying on a bed. Because it is easy for the drug to remain in the suspension cup or in the syringe, which would strongly influence the final collection rate obtained in this study, only $5.0 \mathrm{~mL}$ of the solution was drawn up into the injector. It was injected at a flow rate of $1-2 \mathrm{~mL} / \mathrm{second}$ at a $45^{\circ}$ angle while agitating it. Subsequently, $5.0 \mathrm{~mL}$ of $37^{\circ} \mathrm{C}$ tap water was added to a new injector, and a passage solution was collected by injecting it at the same injection angle and flow rate that was used for injecting the drug solution. This passage solution was then desiccated for $9 \mathrm{~h}$ at $60^{\circ} \mathrm{C}$ in a laboratoryuse dry heat sterilizer (Yamato Scientific Co., Ltd., Tokyo, Japan), after which the mass of the sample was measured. The mass of the suspension cup was accurately measured for the set dose of each drug, and then $10.0 \mathrm{~mL}$ of $37^{\circ} \mathrm{C}$ tap water was added to make a solution. These solutions were not passed through the injector or feeding tube and desiccated by the same methods as the samples. The mass of these control samples was then measured. The collection rate was calculated by subtracting the mass of the experimental samples from the mass of the control samples. For antiepileptic drugs, this was done thrice for every dosage form. For potassium supplements, this was done six times for every dosage form. A new set of injector and feeding tube was used for every trial. Cases in which the feeding tube was obstructed by a drug or if the injector would not go down were considered obstructions, and the collection rate at that point was determined by measuring the mass of drug collected after desiccation.

Statistical Analysis Student's $t$-test was used for comparisons between two groups, and Tukey's tests were used for comparisons among three groups. The statistical analysis software IBM SPSS Statistics version 22 was used for analysis. A significance level of 0.05 was used for both of these tests.

\section{Results}

Temperature Measurement of Powder before and after Use of the Grinder The room temperature at the time of the test was $23.2^{\circ} \mathrm{C}$, the average temperature (standard deviation) of lactose before pulverization was $24.0^{\circ} \mathrm{C}(0.0)$. The average temperature of lactose after pulverization (standard deviation) was $27.0^{\circ} \mathrm{C}(0.6)$.

Antiepileptic Drug Passage Tests All the dosage forms of all the drugs, except for topiramate powdery form, had mean collection rates of about $>90 \%$. The standard deviation of the collection rates was $<5 \%$. Moreover, pulverized powdery form and pulverized tablets both had high mean collection rates compared with the powdery form drugs. Two times out of three, topiramate powdery form caused obstructions in the tube, but pulverized topiramate powdery form and pulver- 
ized topiramate tablets did not cause obstructions. The average collection rates (standard deviation) of topiramate powdery form, pulverized powdery form, and pulverized tablets were $37.7 \%$ (47.6), 93.6\% (1.0), and 95.4\% (1.6), respectively. The mean collection rate of the powdery form was lower those of the pulverized powdery form and pulverized tablets, and the standard deviation was also larger (Table 2).

Potassium Supplement Passage Tests Potassium L-aspartate powdery form caused obstructions three out of six times, but the pulverized powdery form did not cause any obstructions. The mean collection rates (standard deviation) of potassium L-aspartate powdery form and pulverized powdery form were $51.6 \%$ (18.5) and 76.4\% (2.1), respectively. The collection rate for pulverized powdery form was significantly higher than that of the powdery form $(p=0.008)$. The mean collection rate of potassium gluconate powdery form and pulverized powdery form were $>90 \%$. The standard deviation of the collection rates was $<5 \%$. The collection rates of potassium gluconate powdery form and pulverized powdery form were higher than that of potassium L-aspartate pulverized powdery form (Table 3).

\section{Discussion}

When oral administration is not possible for newborn infants, administration via feeding tube is recommended. ${ }^{12)}$ In such cases, drugs are administered via feeding tube. Obstructions of this tube can affect treatment and also increase the burden on the patient and caregivers. ${ }^{2}$ The efficacy and expression of the side effects of the pulverized drugs investigated in the current study may undergo changes owing to this pulverization ${ }^{13)}$; however, in neonatal care, wherein the obstruction of feeding tubes and the loss of drugs owing to administration via feeding tube have considerable effects, the use of pulverized drugs should be considered.

In this study, a grinder was used to pulverize the powder. To investigate the effect of heat generated during use of the grinder on the drug, we compared the lactose temperature be- fore and after using the grinder. The temperature slightly increased but was below body temperature. Therefore, the effect of the heat generated when using the grinder on the drug is considered to be negligible.

In the current study, the collection rates of antiepileptic drug pulverized powdery form and pulverized tablets were higher than that of powdery form, which suggests that these dosage forms do not result in a loss of the drug owing to administration via feeding tube. This could be because pulverization makes the granule size smaller, thereby increasing the drug's solubility. ${ }^{14)}$ The effects of pulverization on the stability and pharmacokinetics of several powdery form drugs have not been explained. The effects of pulverized tablets on pharmacokinetics have not been elucidated; however, there is information on the stability of pulverized tablets ${ }^{15)}$; therefore, pulverized powdery forms should only be chosen over pulverized tablets if the collection rate of the latter is markedly higher than the former. With the exception of topiramate, the antiepileptic drug powdery forms had favorable collection rates of about $>90 \%$. The standard deviation of the collection rates was small; thus, these are believed to be more suitable dosage forms for administration via feeding tube as the stability and safety have been confirmed. Neither topiramate pulverized powdery form nor pulverized tablets cause tube obstructions. Although the influence on the pharmacokinetics has not been elucidated for pulverized topiramate tablets, the collection rate increased to $>90 \%$, which suggests that it is stable after pulverization. ${ }^{16)}$ It is believed to be a more suitable dosage form for administration via feeding tube. As demonstrated in this study, some drugs, such as topiramate, require careful choice of dosage form. Care should be taken with regard to losses during tube administration and occlusion of the tube because they can cause seizures. Prior to clinical use, careful consideration is required.

Pulverized potassium L-aspartate powdery form and potassium gluconate did not cause tube obstructions; both supplements could pass through the feeding tube. However,

Table 2. Collection Rate of Antiepileptic Drugs

\begin{tabular}{|c|c|c|c|c|c|}
\hline \multirow{2}{*}{ Active ingredient } & \multicolumn{3}{|c|}{ Collection rate ${ }^{a)}(\%)$} & \multicolumn{2}{|c|}{$p$-Value $\mathrm{e}^{b)}$} \\
\hline & $\begin{array}{l}\text { Powdery form } \\
\quad(n=3)\end{array}$ & $\begin{array}{l}\text { Pulverized powdery form } \\
\qquad(n=3)\end{array}$ & $\begin{array}{l}\text { Pulverized tablets } \\
\qquad(n=3)\end{array}$ & $\begin{array}{l}\text { Powdery form } v s \text {. } \\
\text { Pulverized powdery form }\end{array}$ & $\begin{array}{l}\text { Powdery form } v s \text {. } \\
\text { Pulverized tablets }\end{array}$ \\
\hline Carbamazepin & $90.5(0.3)$ & $94.9(0.3)$ & $92.0(0.3)$ & $<0.001$ & 0.002 \\
\hline Clonazepam & $96.1(1.2)$ & $97.3(1.8)$ & $96.3(2.1)$ & 0.667 & 0.992 \\
\hline Zonisamide & $94.0(2.0)$ & $96.1(0.6)$ & $95.1(4.8)$ & 0.683 & 0.889 \\
\hline Topiramate & $37.7(47.6)$ & $93.6(1.0)$ & $95.4(1.6)$ & 0.104 & 0.094 \\
\hline Phenytoin & $94.0(0.5)$ & $95.2(0.5)$ & $91.3(0.9)$ & 0.126 & 0.006 \\
\hline Primidone & $92.6(0.5)$ & $93.8(0.5)$ & $89.2(2.5)$ & 0.624 & 0.079 \\
\hline Levetiracetam & $97.3(1.6)$ & $97.3(0.5)$ & $97.5(1.2)$ & 0.999 & 0.975 \\
\hline
\end{tabular}

a) Average (standard deviation: S.D.), b) Tukey's test, versus: vs.

Table 3. Collection Rate of Potassium Supplement

\begin{tabular}{lccc}
\hline \hline \multirow{2}{*}{ Active ingredient } & \multicolumn{2}{c}{ Collection rate $^{a)}(\%)$} & $p$-Value \\
\cline { 2 - 3 } & Powdery form $(n=6)$ & Pulverized powdery form $(n=6)^{b)}$ \\
\hline Potassium L-aspartate & $51.6(18.5)$ & $76.4(2.1)$ & 0.008 \\
Potassium gluconate & $101.2(4.3)$ & $96.2(2.4)$ & 0.033 \\
\hline
\end{tabular}

a) Average (S.D.), b) Student's $t$-test. 
pulverized potassium L-aspartate powdery form had a collection rate of $70 \%$, whereas the collection rates of all potassium gluconate dosage forms were $>90 \%$. Additionally, pulverized potassium L-aspartate powdery form and potassium gluconate had low standard deviations for their collection rates. Because of this, potassium gluconate is believed to be suitable for feeding tube. It is important to evaluate collection rates, not just passage through the tube, when investigating the more suitable dosage forms and drugs for administration via feeding tube.

The current study was conducted based on the feeding tube administration conditions used at our hospital; however, there are reports of different amounts of solution, types of tube, and flush conditions. ${ }^{3,17,18)}$ Furthermore, we used new tubes each time to keep the conditions for each of the passage tests in the current study consistent. In clinical practice, the same tube may be repeatedly used, which could allow drugs to accumulate in the tube or change the passage through the tube owing to wear; thus, further studies are needed on this topic. In this study, the main component was not measured, and it is unknown whether the loss of the drug was due to the loss of the main component. However, in this study, as shown in the results for topiramate and potassium, it is very useful in evaluating the passability when changing the drugs. Furthermore, since it is a simple method, it is considered to be useful in that it can be examined even in a hospital without a special measuring device.

In the current study, we determined the more suitable dosage form and drug that had the least loss by evaluating the collection rate using passage experiments for neonatal feeding tubes. The influence of the loss of drug during administration via feeding tube is believed to have a large influence on treatment efficacy; thus, the results of the current study are useful for the selection of drugs for administration via feeding tube. In the future, we plan to study other drugs and evaluate not only passage but also drug loss using the collection rate as an indicator to further study the more suitable forms and drugs for administration via feeding tube.

Acknowledgments This work was supported by clinical research support office in Kanazawa Medical University.
Conflict of Interest The authors declare no conflict of interest.

\section{References}

1) Trier E., Thomas A. G., Nutrition, 14, 801-805 (1998).

2) Riss J. R., Kriel R. L., Kammer N. M., Judge M. K., Montgomery M. J., Pediatr. Neurol., 27, 193-195 (2002).

3) Ponrouch M. P., Sautou-Miranda V., Boyer A., Bourdeaux D., Montagner A., Chopineau J., Int. J. Pharm., 390, 160-164 (2010).

4) Beckwith M. C., Feddema S. S., Barton R. G., Graves C., Hosp. Pharm., 39, 225-237 (2004).

5) Devlin J. W., Bakshi A., Bungay K., Olsen K. M., Aliment. Pharmacol. Ther., 24, 1603-1611 (2006).

6) Taketomo C. K., "Pediatric \& Neonatal Dosage Handbook with International Trade Names Index," 21st ed., Lexi-Comp Inc., Hudson, 2014.

7) White R., Bradnam V., "Handbook of Drug Administration via Enteral Feeding Tubes," 3rd ed., Pharmaceutical Press, London, 2015.

8) Gracia-Vásquez S. L., González-Barranco P., Camacho-Mora I. A., González-Santiago O., Vázquez-Rodríguez S. A., Medicina Universitaria, 19, 50-63 (2017).

9) Rennie J. M., Boylan G. B., Curr. Opin. Neurol., 16, 177-181 (2003).

10) Niimura T., Zamami Y., Imai T., Ito T., Sagara H., Hiroyuki H., Esumi S., Takechi K., Imanishi M., Koyama T., Amano M., Kurata N., Kitamura Y., Nakura H., Sendo T., Ishizawa K., J. Med. Invest., 65, 32-36 (2018).

11) Ruzsíková A., Součková L., Suk P., Opatřilová R., Kejdušová M., Srámek V., Int. J. Pharm., 478, 368-371 (2015).

12) Andrew M. J., Sullivan P. B., Paediatr. Child Health, 20, 321-326 (2010).

13) Cornish P., CMAJ, 172, 871-872 (2005).

14) Boullata J. I., Am. J. Nurs., 109, 34-42, quiz, 43 (2009).

15) Gilbar P. J., Pract D. H. C. P., J. Pain Symptom Manage., 17, $197-$ 207 (1999).

16) Faught E. Jr., Neuropsychiatr. Dis. Treat., 3, 811-821 (2007).

17) Fujioka K., Kuroda J., Yamana K., Iijima K., Morioka I., Pediatr. Int., 59, 1174-1177 (2017).

18) Wohlt P. D., Zheng L., Gunderson S., Balzar S. A., Johnson B. D., Fish J. T., Am. J. Health Syst. Pharm., 66, 1458-1467 (2009). 